\title{
A Teoria da Subjetividade e seus conceitos centrais
}

\author{
Theory of Subjectivity and its main concepts
}

\author{
Elias Caires de Souza ${ }^{1}$ \\ José Fernando P. Torres ${ }^{2}$
}

\begin{abstract}
RESUMO
Este artigo aborda os conceitos fundamentais desenvolvidos por González Rey em sua Teoria da Subjetividade. Apresentaremos as definições dos conceitos desta teoria, a saber: sujeito, sentidos subjetivos, configurações subjetivas, subjetividade individual e subjetividade social, destacando a estrutura conceitual que suporta o pensamento teórico do autor. A Teoria da Subjetividade fundamenta um caminho investigativo que permite a compreensão dos sentidos subjetivos e configurações subjetivas constituintes dos complexos processos psicológicos humanos produzidos nos diferentes espaços sociais, algo não observado nas abordagens teóricas dominantes na psicologia. O conceito de subjetividade, como definido na teoria, rompe com as dicotomias estabelecidas no pensamento moderno, tais como intelectual/emocional, interno/externo mediante um modelo teórico que assume a psique humana a partir de seu caráter gerador dentro da trama cultural na qual as pessoas e grupos participam. Nessa direção, a Teoria da Subjetividade e seus conceitos abrem possibilidades à geração de novos modelos de inteligibilidade para a compreensão dos múltiplos e singulares processos de subjetivação das atividades humanas em suas diferentes esferas da vida. Palavras-chave: subjetividade, sujeito, sentido subjetivo, configuração subjetiva.
\end{abstract}

\begin{abstract}
This article discusses the fundamental concepts developed by González Rey in his Theory of Subjectivity. We will present the definitions of the concepts of this theory, namely: subject, subjective senses, subjective configurations, individual subjectivity and social subjectivity, highlighting the conceptual structure that supports the theoretical thought of the author. The Theory of Subjectivity supports an investigative path that allows the understanding of the subjective senses and subjective configurations that constitute the complex human psychological processes produced in the different social spaces, something not observed in the dominant theoretical approaches in psychology. The concept of subjectivity, as defined in theory, breaks with the dichotomies established in modern thought, such as individual / society, intellectual / emotional, internal / external through a theoretical model that assumes the human psyche from its generative character within the plot in which people and groups participate. In this direction, Theory of Subjectivity and its concepts open possibilities for the generation of new models of intelligibility for the understanding of the multiple and singular processes of subjectivation of human activities in their different spheres of life.
\end{abstract}

Key words: subjectivity, subject, subjective sense, subjective configuration.

\footnotetext{
1 Graduado em Música pela Universidade de Brasília (UnB). Psicólogo pelo Centro Universitário de Brasília (UniCEUB). Pós-Graduado em Psicopedagogia pela Universidade Católica de Brasília (UCB). Mestre e Doutor em Educação pela Universidade de Brasília . Professor de Música no Centro de Educação Profissional da Escola de Música de Brasília (CEP-EMB).

2 Psicólogo, Mestre em Psicologia Cultural - Universidad Del Valle/Colômbia, e Doutor em Educação pela Universidade de Brasília. Professor do programa de Graduação em Psicologia da Universidade Federal do Tocantins.
} 


\section{Introdução}

\section{A Teoria da Subjetividade e sua rede conceitual}

As teorias são processos de significados da realidade humana que só existem nos termos das teorias, e não fora delas" (GONZÁLEZ $R E Y, 2014, p .32)$.

O termo subjetividade, no pensamento psicológico dominante, carregou consigo duas formas de reducionismo: por um lado, o reducionismo intrapsíquico o qual enclausurou a psique humana no próprio indivíduo, isto é, definiu a dinâmica psíquica nos processos psicológicos individuais; por outro, também foi dominante a concepção social determinista, que acreditava que a psicologia humana estava diretamente orientada por influências externas que agiam sobre o homem, determinando seus comportamentos. Ambas as formas de pensar a subjetividade estiveram cristalizadas na dicotomia individual/social, desconsiderando as dimensões cultural, social e histórica no fluxo dos processos psicológicos complexos, bem como, a capacidade autogeradora da psique.

Contudo, na análise da concepção dominante da subjetividade, que sinaliza sua esterilidade heurística enquanto categoria teórica para a produção de conhecimento sobre as formas complexas constituintes da psicologia humana, González Rey dá um giro na categoria no desenvolvimento de sua Teoria da Subjetividade (1997, 2002, 2005, 2007a, 2012a, 2014, 2016, 2017b, 2019). Então, por que ele se apoia nesta categoria para pensar uma via epistemológica geradora de novas significações à complexa organização dos fenômenos psicológicos especificamente humanos? González Rey nos oferece a seguinte resposta:

Acredito que, apesar da conotação metafísica, racionalista e individualista que o termo subjetividade tomou na história do pensamento psicológico e filosófico ocidental, ele tem representado uma opção de significação para processos de uma qualidade singular, em cuja definição intervém a qualidade do sujeito que os produz, qualidade que não é definida apenas por uma expressão racional, mas por uma expressão simbólico-emocional, que caracteriza a produção psíquica nos diferentes espaços e áreas da vida humana (GONZÁLEZ REY, 2007a, p. 129). 
O giro conceitual introduzido por González Rey tem permitido diversos desdobramentos e aportes para a psicologia, a educação e as áreas de conhecimento afins. De acordo com o autor, a subjetividade é:

\begin{abstract}
A forma compleja en que lo psíquico humano toma lugar en el desarrollo de las personas y de todos los procesos humanos. A diferencia del subjetivismo, la subjetividad nos permite una concepción de mente que es inseparable de la historia, la cultura y los contextos actuales de la vida social humana. La subjetividad emerge cuando la emoción pasa a ser sensible a los registros simbólicos, permitiendo al hombre una producción sobre el mundo em que vive, y no simplemente la adaptación a él. (GONZÁLEZ REY; PATIÑN, 2017, p. 123):
\end{abstract}

Da definição anterior destacamos a importância dada por González Rey a uma categoria esquecida no pensamento racionalista da ciência moderna: a emoção. Subjetividade, retomando a citação, é justamente quando a emoção e o simbólico se constituem como unidade geradora de sentidos e configurações subjetivas. A emoção, nesta concepção, não só é revitalizada, mas compreendida para além da visão naturalista das respostas apresentadas perante o ambiente (GONZÁLEZ REY, 2017b).

Complementando o anterior Mitjáns Martinez, colaboradora permanente de González Rey, no curso da elaboração de sua teoria, concebe que a subjetividade é:

Tanto social quanto individual constituindo-se mutuamente. Não é possível considerar a subjetividade de um espaço social desvinculada da subjetividade dos indivíduos que a constituem; do mesmo modo, não é possível compreender a constituição da subjetividade individual sem considerar a subjetividade dos espaços sociais que contribuem para sua produção (MITJÁNS MARTINEZ, 2005, p. 20).

O campo epistemológico subjacente às citações anteriores destaca pontos importantes para a compreensão da subjetividade enquanto uma "expressão ontológica de um fenômeno especificamente humano, social, individual, nas condições da cultura, que se desprende do psiquismo” (GONZÁLEZ REY, 2017a, p. 207). Assim, temos que a subjetividade: 1) tem um caráter processual, singular 
e gerador da psique humana; 2) inclui a consideração dos processos simbólicoemocionais nas produções psicológicas emergentes no curso das ações do sujeito; 3) abarca as dimensões individual e social entrelaçadas como unidade no curso das experiências da pessoa; 4) dá destaque ao sujeito, enquanto posicionamento subjetivo fundamental na qualidade de suas experiências.

Noutro momento de sua obra, González Rey vai sublinhar que a subjetividade:

É uma produção do sujeito que tem como matéria-prima sua vida social e a cultura, porém, não existe nenhum tipo de relação direta entre o caráter objetivo de uma experiência vivida e a forma em que ela influencia o desenvolvimento psíquico da pessoa. Esse desenvolvimento está sempre metamorfoseado por uma produção de sentidos subjetivos que se definem na configuração subjetiva da experiência vivida (GONZÁLEZ REY, 2012a, p.34).

O conjunto dos trechos teóricos apresentados evidencia o caráter complexo, sistêmico e em desenvolvimento da subjetividade, posto que sempre está implicada com as condições de sua produção pelo sujeito. Nesse sentido, González Rey registra que a subjetividade é:

Um sistema em desenvolvimento permanente, implicado sempre com as condições de sua produção, embora com uma estabilidade que permite definir os elementos de sentido constituintes das configurações dominantes do sujeito em relação às principais atividades e posições que o ocupam em cada momento concreto da vida (GONZÁLEZ REY, 2009a, p.173).

A concepção de subjetividade enquanto sistema em constante desenvolvimento, articulado com as condições de sua produção, nos permite pensar que a pessoa não se constitui apenas enquanto respostas às questões de ordem fisiológica, psicológica, laboral, afetiva, familiar, social em uma relação direta. Essa forma de pensar a subjetividade como sistema rompe os determinismos socioculturais e biológicos que têm caracterizado a história do pensamento psicológico. 
Neste momento é importante um esclarecimento. Sendo a matriz da subjetividade histórica e cultural, ela não se limita à história e à cultura na qual os indivíduos são socializados. A produção subjetiva depende dos espaços de subjetivação que são produzidos dentro da cultura e da experiência vivida no tempo subjetivo das pessoas, mas dita produção não é um efeito direto dos repertórios proporcionados pela própria cultura, a saber: rituais, práticas, concepções e símbolos. É por isso que a subjetividade, dentro da sua processualidade, mantém uma relação paradoxal com a cultura e a história: por um lado, se constitui nelas; mas por outro - e devido ao seu caráter gerador -, sua produção se singulariza, rompendo com as restrições que impõem a cultura e a história (GONZÁLEZ REY; MITJÁNS MARTÍNEZ, 2017).

Ao examinarmos a subjetividade como plataforma teórica de pensamento nas citações anteriores, temos uma relação estreitamente articulada entre os conceitos constituintes da teoria, quais sejam: sentido subjetivo, configuração subjetiva, sujeito, subjetividade social e subjetividade individual. Desse modo, a rede conceitual tecida organiza e expressa um sistema teórico recursivo, vivo e dinâmico que supera a classificação de elementos isolados em definições estanques (GONZÁLEZ REY, 2014), permitindo a abertura de novas zonas de inteligibilidade sobre o psiquismo humano.

Nas linhas a seguir, abordaremos os conceitos centrais da Teoria da Subjetividade.

\section{Sentido Subjetivo}

Os sentidos subjetivos são a unidade básica da subjetividade, a qual está constituída pela unidade entre o simbólico e o emocional. Ao pensar a categoria sentido subjetivo, González Rey partiu da compreensão do termo sentido do psicólogo russo Lev S. Vygotsky. Para este autor, o sentido está associado à palavra sendo entendido como a "unidade que reflete a conjunção do pensamento e da linguagem" (VYGOTSKY, 2007, p. 315). Ainda segundo Vygotsky, o sentido emerge como a "soma de todos os fatos psicológicos que a palavra desperta em nossa consciência" e que "o sentido real da palavra é determinado, no fim das contas, por 
toda a riqueza dos momentos existentes na consciência e relacionados àquilo que está expresso por uma determinada palavra" (VYGOTSKY, 2000, p.465).

Embora o sentido esteja relacionado com a palavra e com os elementos psicológicos da consciência, Vygotsky dá um significativo passo ao considerar o sentido como uma categoria psicológica (GONZÁLEZ REY, 2012b), apesar de a elaboração teórica sobre o termo ter ficado incompleta em sua obra, devido a falta de recursos teóricos para compreender o potencial ontológico da noção de sentido para o desenvolvimento da psicologia, como também, a sua morte prematura (GONZÁLEZ REY, 2009b). Assim, o sentido expressou uma categoria teórica inconclusa, mas abriu "una posibilidad para el desarrollo de una nueva unidad psicológica" (GONZÁLEZ REY, 2010, p. 252), orientada à geração de novas inteligibilidades às produções psicológicas humanas, fundamentadas em uma perspectiva históricocultural.

Tomando como matéria-prima a conceito de sentido em Vygotsky, González Rey enxerga nela um valor heurístico para o conhecimento das formas complexas das configurações psicológicas do ser humano. Desse modo, ele elabora uma reformulação do conceito como o objetivo de:

Avanzar en una teoría cultural-histórica sobre la subjetividad que, como la conciencia, siempre apareció referida de forma general e imprecisa en las ciencias sociales y en la propria filosofía, siendo tratada de forma marginal en el tratamiento de otros temas (GONZÁLEZ REY, 2011b, p. 312).

Como resultado de tal reformulação, González Rey apresenta a categoria sentido subjetivo (2005), a qual está associada aos processos simbólicos e emocionais emergentes no curso das experiências e ações da pessoa e, portanto, se desprendendo de uma correlação com a palavra e os elementos psicológicos da consciência, conforme entendido por Vygotsky.

O termo subjetivo, no conceito de González Rey, expressa "as complexas integrações simbólico-emocionais que se organizam de forma simultânea no curso de uma experiência vivida e no sujeito dessa experiência” (GONZÁLEZ REY, 2012a, p.62). Com isso, o termo subjetivo não se trata de uma adjetivação que acompanha a palavra sentido, mas diz-nos dos diferentes elementos substantivos 
com os quais o sentido ganha vida e contornos, os quais serão teoricamente conhecidos nas configurações subjetivas.

O sentido subjetivo é definido como "a unidade inseparável dos processos simbólico e emocional num mesmo sistema, no qual a presença de um desses elementos evoca o outro, sem que seja absorvido pelo outro" (GONZÁLEZ REY, 2005, p.127). Como unidades simbólico-emocional, os sentidos subjetivos formam uma rede subjetiva maleável e em constante fluxo que não expressam uma linearidade com os fatos concretos da vida social e individual da pessoa. Eles resultam "de uma rede de eventos e de suas consequências colaterais, que se expressam em complexas produções psíquicas" (GONZÁLEZ REY, 2007b, p.172).

Como apresentado por González Rey:

O sentido subjetivo destaca a emergência de um novo tipo de produção psíquica que não aparece como ato intencional da pessoa, mas como uma nova qualidade da psique humana que especifica o status subjetivo da experiência vivida. O sentido subjetivo é o resultado da configuração subjetiva que se organiza em torno da experiência vivida. Ele é o resultado de uma configuração subjetiva que se organiza no curso da própria experiência e da qual participam ativamente, em forma de sentidos subjetivos diversos, as diferentes configurações da personalidade envolvidas nesse processo (GONZÁLEZ REY, 2012a, pp. 27-28).

$\mathrm{Na}$ citação acima, os sentidos subjetivos representam o qualificador subjetivo dos fatos concretos por nós vividos, ou seja, ele expressa o caráter subjetivo de tais vivências em configurações subjetivas que se organizam no curso daquelas experiências e que não é uma resposta linear frente ao vivido, mas uma expressão ontológica da psique humana destacando-se seu caráter gerador. É por isso que a experiência subjetiva é uma produção que integra o social e o individual em unidades singularizadas de produção subjetiva.

Os sentidos subjetivos de uma determinada experiência não estão restritos a essa experiência. Eles estão amalgamados com os sentidos subjetivos de outras vivências as quais ganham novos contornos subjetivos no curso da experiência atual. Nessa direção, os sentidos subjetivos destacam a singularidade e complexidade de uma vivência que, teoricamente, rompe com a padronização e universalização na compreensão dominante dos fenômenos psicológicos. 
Ainda com a citação anterior, observamos a importância do sujeito na qualidade de suas produções psíquicas. Embora os sentidos subjetivos não sejam uma produção consciente da pessoa, o modo como ela interage com os muitos elementos definidores do momento concreto está recursivamente associado com as diferentes configurações de sua personalidade, substanciando a configuração subjetiva daquele instante e, desse modo, convergindo múltiplos sentidos subjetivos de origens diversas.

A epistemologia que fundamenta o arcabouço conceitual da Teoria da Subjetividade e, dessa forma, orienta a compreensão e a investigação da especificidade dos fenômenos psíquicos humanos, sublinha que os sentidos subjetivos de uma experiência não podem ser conhecidos a priori e nem intencionalmente produzido pela pessoa no ato concreto da ação ou definido por conteúdos intrinsecamente associados ao fato vivido.

Nas palavras de González Rey "los sentidos subjetivos definen el aspecto subjetivo da experiencia vivida y existen no como contenidos puntuales, susceptibles de expresión concreta por el sujeto [...]" (GONZÁLEZ REY, 2009c, p. 217). Uma lógica positiva aplicada à compreensão dos sentidos subjetivos se mostrará ineficiente na elucidação de suas supostas causas já que, a "lógica" que os regem, apresenta uma dinâmica ontológica que lhes confere formas próprias de organização e desenvolvimento. (CAIRES, 2017).

A plasticidade e o fluxo dinâmico dos sentidos subjetivos geram uma teia de sentidos subjetivos que se organizam em configurações subjetivas as quais expressarão os sentidos dominantes de uma atividade. Assim, sua inteligibilidade só é possível:

No momento de interpretação da configuração subjetiva, que é o que permite captar os sentidos subjetivos dominantes, presentes na expressão plural da pessoa que aparece, de forma simultânea, em cada momento da ação concreta (GONZÁLEZ REY, 2011a. p. $34)$.

Os sentidos subjetivos são, com as configurações subjetivas, elementos centrais para a compreensão do modo subjetivo como vivemos a vida em suas dimensões social e individual, as quais, como destacado anteriormente, 
constituem qualidades diferentes de um processo de subjetivação, e não instâncias dicotômicas como consagrado no pensamento dominante conferindo ao social uma espécie de domínio sobre o individual.

Em sua multiplicidade de origens, os sentidos subjetivos implicam processos diferentes e simultâneos. Desse modo, as qualidades transitória, maleável, instantânea e dinâmica dos sentidos subjetivos envolvidas naqueles processos, não permitem seu "aprisionamento" a nenhuma significação determinista de uma experiência ou definição antecipada do resultado de seus percursos. O movimento interminável gerador de sentidos subjetivos no curso de nossas experiências organizarão, em novas produções subjetivas, o encontro do passado com o presente.

Nesse entendimento, as experiências não se sobrepõem ou anulam-se umas às outras no curso de novos fatos vividos. Elas são subjetivamente transformadas por novas produções de sentidos subjetivos as quais rompem com a ideia de que os fatos concretos, na origem das experiências, formatam seus desenvolvimentos. $\mathrm{O}$ processo de subjetivação subjacente às nossas vivências caminha por vias imprevisíveis à conscientização. Mesmo que exista consciência de determinado ato ou momento vivido, esta já é uma produção de sentidos subjetivos posto que, emergente de múltiplas vias de sentidos subjetivos e não diretamente oriunda daquele momento ou ato concreto.

Há um fio subjetivo condutor de nossas experiências, cuja qualidade de sua condução reside no fluxo constante e interminável de produções de novos sentidos subjetivos. Estes são:

The key subjective units whose endless movement engenders other forms of subjective formations. The subjective senses are the instantaneous emotional-symbolic units that characterize the flux of human experience as life is subjectively lived. Subjective senses are the paths by which the past and the diversity of present experiences lived by individuals within different social instances are integrated into one subjective configuration. (GONZÁLEZ REY, 2017b, p. 183). 


\section{Configuração Subjetiva}

Dentro do desenvolvimento teórico de González Rey, a categoria configuração subjetiva foi apresentada na publicação Comunicación, personalidad y desarrollo, como:

La integración de múltiples elementos dinámicos en torno a un sentido psicológico específico, por lo que se puede incluir una configuración dentro de otra no como elementos diferentes que se integran, sino como parte de un nuevo nivel cualitativo de organización psíquica (GONZÁLEZ REY, 1995, p. 59).

A ideia de configuração subjetiva como integradora dos múltiplos elementos dinâmicos em torno de um sentido psicológico específico sinaliza uma produção dominante de sentidos subjetivos. Ela destaca uma configuração subjetiva como uma organização relativamente estável frente ao fluxo caótico e imprevisível que governam os sentidos subjetivos.

Como organização subjetiva das diferentes produções de sentidos subjetivos emergentes nas vivências do sujeito, a categoria configuração subjetiva permitenos inteligibilidade teórica para os modos singulares com os quais o ser humano organiza suas experiências sem, contudo, esgotá-las nas configurações emergentes.

A configuração subjetiva é a "organização subjetiva de um campo de experiência do sujeito", e não um conjunto de elementos constituintes dessa experiência, os quais podem "variar em intensidade, mas que não são os mesmos para todos os sujeitos" (GONZÁLEZ REY, 2009a, p.175). Com essa sentença, o autor nos diz que a configuração subjetiva pode ter um tipo de organização semelhante para diferentes sujeitos, mas que está integrada por elementos de sentidos completamente diferentes.

Noutro momento de sua obra, González Rey afirma que as configurações subjetivas são:

Los sistemas de sentido subjetivo que se organizan como formaciones psicológicas de la subjetividad individual. Una configuración subjetiva es una fuente permanente de producción de sentidos subjetivos en relacíon a todo o campo de actividad y - o 
relaciones significativas de la persona (GONZÁLEZ REY, 2007c, p.20).

As configurações subjetivas não representam a priori determinantes da ação. Elas são constituintes do sentido subjetivo que uma ação tem, mas "ellas no 'dirigen' los sentidos subjetivos que se van desarrollando en la acción; ellas son un momento inseparable en la producción de esos sentidos subjetivos" (González Rey, 2009c, p.218).

As configurações subjetivas são maleáveis e sensíveis às diferentes vivências engendradoras de sentidos subjetivos. O fluxo contínuo e variável de seus modos de organizações sinaliza um fio condutor marcado por relativa estabilidade na qual as possibilidades e limitações à geração de novas configurações subjetivas estão associadas à capacidade da pessoa, enquanto sujeito, de gerar recursos personológicos no curso de uma ação, capazes de pôr em jogo um posicionamento subjetivo produtor de novos sentidos subjetivos os quais estarão, recursivamente, na base das novas configurações subjetivas do vivido.

Assim, Gonzalez Rey nos diz:

Unlike subjective senses, subjective configurations represent relatively stable psychological systems, but they never have human expressions as external causes. Subjective configurations are very malleable, taking different forms according to the context and to a particular individual's psychological state at the moment of that concrete experience (GONZÁLEZ REY, 2012b, p. 54).

As citações acima evidenciam o jogo entre as configurações subjetivas e os sentidos subjetivos cuja dinâmica estabelece uma recursividade entre ambas não havendo reciprocidade, correlação, entre uma e outra. A processualidade desse intercâmbio vivo faz com que as configurações subjetivas de um campo experiencial da pessoa se articulem com as configurações de outras vivências, pois os sentidos subjetivos - por suas qualidades múltipla, circulante e sistêmica vão atravessando estes diferentes momentos de experiências operando novas organizações subjetivas na experiência atual.

Por integrar os sentidos subjetivos emergentes dos múltiplos espaços da vida social da pessoa, as configurações subjetivas representam uma produção 
dominante de sentidos subjetivos em relação a determinado campo da experiência, mas não emerge exclusivamente desse campo ou se esgota nele. Assim, a categoria nos permite estudar, por exemplo, a configuração subjetiva dominante vinculada aos processos de aprendizagem de uma determinada pessoa, a qual expressa um valor heurístico tanto para a compreensão do complexo fenômeno do aprender, como para a própria prática profissional de natureza pedagógica.

A compreensão da configuração subjetiva como categoria teórica sinaliza o giro epistemológico proposto para a geração de inteligibilidade aos fenômenos psíquicos humanos em seus diferentes campos de experiências. Um avanço teórico é destacado ao romper com noções conteudistas, generalizadoras e universais atribuídas aos fenômenos psíquicos, os quais são estéreis para estudar as formas complexas e singulares de organização e desenvolvimento subjetivos, obscurecendo os caminhos plurais e inesgotáveis com os quais as pessoas organizam suas experiências em diferentes momentos da vida.

$\mathrm{Na}$ abordagem do autor, "não existem configurações de sentidos universais, posto que elas se formam e se desenvolvem na produção subjetiva diferenciada do sujeito nos diferentes campos de suas atividades" (GONZÁLEZ REY, 2009a, p.175). Assim, González Rey e Mitjáns Martínez afirmam que:

El concepto de configuración subjetiva es una definición teórica que, por su complejidad y movilidad, adquiere valor epistemológico, pues inaugura un tipo de concepto al que no se puede asimilar lo empírico de forma directa, y tampoco sirve para describir lo empírico. El concepto de configuración subjetiva es producido teóricamente en el curso del momento empírico de la investigación (GONZÁLEZ REY; MITJÁNS MARTÍNEZ, 2016, p.

\section{Sujeito} $15)$.

A categoria sujeito tem sido abordada por diferentes campos do saber e variadas são as definições e tentativas de representações teóricas para essa categoria (LIBERA, 2013; BATTISTI, 2010). Neste tópico, partindo da abordagem de González Rey à categoria em questão, destacaremos a importância dessa 
categoria e sua estreita articulação com os demais conceitos da Teoria da Subjetividade.

Para González Rey, o sujeito está conceituado como:

El individuo capaz de generar espacios propios de subjetivación y desarrollo dentro de los diferentes espacios sociales de su vida cotidiana. Hemos querido destacar con la idea de sujeto la condición individual reflexiva, crítica e asumida, capaz de generar consecuencias diversas sobre la organización social de los diferentes espacios de acción social de la persona (GONZÁLEZ REY, 2007c, pp. 20-21).

Nessa citação, observamos uma distinção entre dois termos que comumente são tomados como sinônimos: sujeito e indivíduo. Para o autor, o indivíduo, na qualidade de sujeito, é alguém com capacidade para abrir caminhos subjetivos nos espaços da vida social dominante, o que lhe permite romper com as limitações imediatas que determinada situação ou institucionalização do cotidiano apresenta. Assim, a condição de sujeito é fulcral para a geração de rotas alternativas aos enfrentamentos da vida, geração essa, mobilizada e movimentada por uma cadeia de sentidos subjetivos do sujeito, organizada mediante configurações subjetivas no percurso de sua história social.

Como destacado pelo autor, as condições reflexiva, crítica e assumida ante os múltiplos contextos da vida implicam a responsabilidade que tem o sujeito com sua capacidade autoral na modificação das tramas sociais com as quais interage. Nessa perspectiva, ele não responde linearmente aos fatos do cotidiano e, tampouco, são suas características físicas, sociais, culturais e psicológicas as determinantes geradoras de uma classe de respostas frente aos cenários da vida. Dessa forma, o sujeito emerge nos espaços de tensão "gerando um caminho alternativo de subjetivação dentro dos espaços normativos institucionais" (GONZÁLEZ REY, 2017a, p.58).

Importante salientar que o conceito de sujeito, como apresentado por González Rey, não representa uma condição universal que o indivíduo porta ou não. Ser sujeito não significa uma condição com a qual nascemos ou adquirimos na trajetória da vida. Antes, é uma "condição que se conquista de forma 
permanente no processo de ação e relações que acompanham um processo de subjetivação" (GONZÁLEZ REY, 2007a, 184).

É a capacidade de gerar e movimentar recursos subjetivos, no campo das tensões com o estabelecido, a promotora do indivíduo à condição de sujeito no curso da ação. Contudo, não se é sujeito o tempo todo, ou seja, o sujeito emergirá sempre que as emoções estiverem comprometidas com as ações do indivíduo em diferentes instâncias da vida. Dessa forma, uma pessoa pode ser sujeito em sua vida amorosa e não no trabalho, por exemplo.

Noutro momento de sua obra, González Rey considera como sujeito a pessoa:

Ativamente envolvida na delimitação e desenvolvimento de espaços pessoais dentro das atividades sociais que desenvolve. A pessoa como sujeito é capaz de se posicionar e de se confrontar a partir de seus projetos, pontos de vista e reflexões pessoais, sempre que esses processos representem produções de sentidos subjetivos (GONZÁLEZ REY, 2017a, p. 57).

O sujeito é pessoa ativa, reflexiva, questionadora, confrontadora que não se submete às vozes imperativas, ditatoriais representadas por variados entes institucionais. Porém, o sujeito é o resultado teórico construtivo interpretativo por parte do pesquisador (GONZÁLEZ REY; MITJÁNS MARTÍNEZ, 2017), o que significa que um indivíduo ou grupo não é considerado como sujeito apenas pelos seus comportamentos observáveis. É por isso que um estudante pode ser calado e tímido na sala de aula, com uma aparência comportamental passiva, mas a sua produção subjetiva sobre o aprender pode estar constituída a partir de configurações subjetivas caracterizadas pela inovação, a criatividade e a motivação, por novas formas de pensar o que está sendo estudado. Nesse caso, um pesquisador da subjetividade tem a possibilidade de construir indicadores, dentro do seu modelo teórico, que lhe permitem afirmar, ou não, que essa pessoa se posiciona como sujeito da sua aprendizagem.

O sujeito não é um epifenômeno de outros processos para os quais não teria a condição de construir caminhos alternativos vivenciais, mas representa "uma instância de ruptura geradora capaz de assumir opções diferentes diante da situação em que vive” (GONZÁLEZ REY, 2005, p. 53). Embora esse indivíduo 
esteja subjetivamente constituído, tal constituição pode, em alguns casos, representar uma barreira, em outros, não.

Por ser socialmente constituído, o sujeito pode, no percurso de sua história, subordinar-se aos elementos caracterizadores dos diferentes espaços sociais, ou gerar alternativas que expressam opções singulares dentro de sua socialização nesses espaços (GONZÁLEZ REY, 2004). Assim o "sujeito se exerce na legitimidade de seu pensamento, de sua reflexão e das decisões por ele tomadas. Por elas, ele entra na dinâmica complexa da vida social" (GONZÁLEZ REY, 2004, p. 149).

O sujeito emerge no exercício de suas elaborações singulares de pensamento frente o vivido. É nesse exercício, subjetivamente dinamizado, que o desenvolvimento das possibilidades de ruptura com o instituído ganha força. Aqui, sublinha-se o pensamento como uma produção subjetiva, e não como exclusivamente uma construção racional. Isto não significa que toda forma de pensamento seja uma produção subjetiva. Implica que aqueles pensamentos emergentes no/do processo de subjetivação de uma relação social da pessoa são desdobramentos de sentidos subjetivos de origens múltiplas, os quais, por sua carga simbólico-emocional, singularizarão as tomadas de decisões da pessoa.

Como dito na introdução deste tópico, a abordagem que González Rey designa à categoria sujeito, está recursivamente associada aos demais conceitos centrais de sua teoria, possibilitando "um sistema teórico recursivo e orientado a superar a taxonomia de elementos isolados em definições estanques, o que caracteriza, tão profundamente, a psicologia” (GONZÁLEZ REY, 2014, p.26).

Nessa direção, no seguinte trecho, ao pontuar a categoria de sujeito, temos um exemplo de como a definição de um determinado conceito convoca os demais, sem, contudo, ser sua causa. Assim, temos:

O sujeito representa o indivíduo subjetivado, produtor de sentidos através das configurações subjetivas que caracterizam sua personalidade, imerso de forma permanente nos contextos nos quais atua e se expressa. Esses processos ocorrem na relação contraditória entre as várias necessidades do sujeito, que se definem por configurações subjetivas que entram em jogo em cada um dos espaços sociais de sua ação; e também pelas novas 
necessidades derivadas do contexto em que atua (GONZÁLEZ REY, 2004, pp. 157-158).

O jogo dos conceitos no interior dessa citação destaca que o sujeito é uma qualidade subjetivada do indivíduo, portanto, emergente dos encontros múltiplos e contraditórios dos sentidos subjetivos organizados nas configurações subjetivas do sujeito no curso da ação. Essas configurações subjetivas vão representar, também a confluência das dimensões social e individual na subjetivação das necessidades do indivíduo em cada uma das esferas da vida. Tem-se que um processo de subjetivação ocorre quando uma carga simbólico-emocional matiza a relação do indivíduo em seus diferentes espaços e momentos concretos de ação.

Frisando a importância da categoria sujeito para a compreensão da subjetividade, o autor afirma que:

Is a condition for understanding subjectivity as a living process that integrates the decisions and paths taken by individuals and social instances during ongoing activity'. (GONZÁLEZ REY, 2016, p.180).

\section{Subjetividade Individual e Social}

Como mencionado, a perspectiva teórica de González Rey assume a unidade entre social e o individual nos processos de produção subjetiva, rompendo com duas visões clássicas da psicologia: aquela centrada no indivíduo, por um lado, e a de natureza sócio determinista que considera o indivíduo um reflexo de estruturas maiores. A teoria da subjetividade avança perante essas formas de psicologias (individualista e sociologizante), justamente porque propõe uma nova representação teórico-ontológica que concebe a relação entre indivíduo e sociedade como um sistema configuracional. Por ser configuracional, o sistema também supera a visão estática, naturalista e racionalizante dessas expressões psicológicas anteriormente mencionadas.

A subjetividade é a síntese configuracional e simultânea produzida em dois planos interdependentes: o social e o individual (GONZÁLEZ REY, 2002). Propor 
que existem formas de subjetividades social e individual, cada uma configurada de maneira singular e diferenciada, possibilita ingressar em um campo de estudos que antes era hegemonicamente governado pelas ciências antropossociais e/ou pelas psicologias do indivíduo. A subjetividade social e individual mantém, nos espaços sociais, uma inter-relação constante, tensa e mutuamente constitutiva, sem que a subjetividade social signifique a soma das subjetividades individuais (Rossato e Mitjáns Martínez, 2013).

A subjetividade individual refere-se aos processos e formas de organização subjetiva gerados nas histórias diferenciadas e singulares dos indivíduos (GONZÁLEZ REY, 2011B). Ela representa os processos e formas de organização subjetiva dos indivíduos concretos. Nela aparece constituída, segundo González Rey, "a história única de cada um dos indivíduos, a qual, dentro de uma cultura, se constitui em suas relações pessoais" (2005, p.241). Isso implica que, embora os indivíduos compartilhem espaços sociais aparentemente comuns (família, escola, trabalho, entre outros), cada pessoa gera sentidos subjetivos e configurações subjetivas muito específicas e diferenciadas emergentes no processo de subjetivação de sua experiência.

Segundo Rossato e Mitjáns Martínez, a subjetividade individual:

Se organiza em torno de elementos essenciais na sua compreensão e desenvolvimento: o sujeito e a personalidade que interagem numa relação em que um é momento constituinte do outro sem que seja diluído por ele. O reconhecimento do caráter ativo, gerador, reflexivo e criativo do sujeito coloca a relação com o social em permanente estado de tensão e rupturas, podendo gerar novas unidades de subjetivação individual e social (ROSSATO; MITJÁNS MARTÍNEZ, 2013, p. 290).

A qualidade do sujeito como elemento essencial da subjetividade individual “constitui o momento vivo da organização histórica da sua subjetividade, e que está implicado de forma constante nos diversos espaços sociais dentro dos quais organiza suas diferentes práticas" (GONZÁLEZ REY, 2005, p.241).

A categoria subjetividade social expressa a forma integradora dos sentidos subjetivos e configurações subjetivas emergentes nos múltiplos espaços sociais, 
gerando um sistema no qual as produções subjetivas e configurações subjetivas de determinado espaço social está articulado, recursivamente, com os sentidos e configurações subjetivas de outras esferas sociais. Ao introduzir essa categoria em sua abordagem teórica, González Rey, assim a definiu:

Entendemos como subjetividad social, precisamente el sistema integral de configuraciones subjetivas (grupales o individuales), que se articulan en los distintos niveles de la vida social, implicándose en las distintas instituciones, grupos y formaciones de una sociedad concreta. (GONZÁLEZ REY, 1996, pp. 99-100).

O conceito apresentado supera a clássica dicotomia individual/social na compreensão das formas complexas com as quais diferentes instâncias sociais se configuram. Dessa forma, o social e o individual estão mutuamente constituídos, produzindo um tecido social que representa não a soma dos indivíduos, senão que, uma rede viva e dinâmica de relações sociais de caráter subjetivo expressas nas configurações subjetivas que a organiza. Outro ponto importante a ser destacado é que os distintos grupos e instituições de uma sociedade estão entrelaçados, isto é, suas formações não estão restritas aos elementos objetivos caracterizadores de uma ou outra formação social.

As produções de sentidos subjetivos emergentes nas articulações contraditórias entre as dimensões social e individual e seus efeitos colaterais produzem uma multiplicidade de efeitos nos diferentes níveis da vida social, os quais não aparecem nas formas objetivas e normatizadoras da relação e ação social. González Rey afirma que a subjetividade social é "un sistema de sentidos subjetivos y configuraciones subjetivas que se instala en los sistemas de relaciones entre personas que comparten un mismo espacio social” (GONZÁLEZ REY, 2008, p.235).

A referida instalação dos sentidos subjetivos e das configurações subjetivas nos sistemas de relações daqueles que compartilham o mesmo espaço social não significa dizer que seja possível, desde uma lógica positivista, observar, identificar e descrever no conjunto dos comportamentos individuais, os elementos objetivos constituidores da subjetividade social daquele espaço. Por ser uma configuração subjetiva das diferentes formas da vida social nas quais se 
articulam múltiplos aspectos da vida, a subjetividade social não se define por suas gêneses, bem como, não depende da vontade e das intenções dos indivíduos. Nessa direção, González Rey destaca o valor heurístico do conceito de subjetividade social ao registrar:

El concepto subjetividad social resulta determinante para completar una visión de lo social como dimensión que no está constituida simplemente por hechos de lo social aparentes, observables, sino como sistema configurado subjetivamente, el cual se desarrolla de forma permanente por sus propias necesidades y formas de organización, que van más allá de las diferentes estructuras de la sociedad en sus diferentes momentos, ello impide la administración de su desarrollo desde la intencionalidad actual de los representantes de las diferentes formas de poder constituidas (GONZÁLEZ REY, 1997, p.175).

A subjetividade social como uma expressão do social que está para além dos fatos aparentes, observáveis e objetivos põe em movimento necessidades e formas de organização dos entes sociais que ganham vida própria no curso das tramas dos sentidos subjetivos configuradores daqueles entes, ou seja, as formações sociais e as necessidades em suas bases não respondem linearmente aos elementos concretos presentes nos diversos momentos de uma sociedade. Tais necessidades são produções de sentidos subjetivos que se organizam, qualitativamente, em níveis diferentes na subjetividade social e na individual, os quais estão, recursivamente, entretecidos.

As tramas dos processos sociais, sob a ótica da subjetividade social:

Deixam de ser vistas como externas em relação ao indivíduo, ou como blocos de determinantes consolidados, que adquirem status do "objetivo" diante do sujeito individual, para serem vistos como processos implicados dentro de um sistema complexo, a subjetividade social, da qual o indivíduo é constituinte e, simultaneamente, constituído (GONZÁLEZ REY, 2005, p.202).

As configurações subjetivas organizadoras da subjetividade social não transformam esta numa entidade portadora de características universais, hegemônicas padronizadoras dos múltiplos cenários sociais. A subjetividade social como um sistema complexo: 
Exibe formas de organização igualmente complexas, ligadas aos diferentes processos de institucionalização e ação dos sujeitos nos diferentes espaços da vida social, dentro dos quais se articulam elementos de sentidos procedentes de outros espaços sociais (GONZÁLEZ REY, 2005, p.203).

A dimensão subjetiva resultante do jogo subjetivado entre as esferas sociais, bem como o modo complexo em que ela aparece em cada ente social, põem em relevo o valor heurístico do conceito de subjetividade social para a geração de visibilidade às múltiplas e inesgotáveis formas de organização de uma sociedade e seus espaços institucionais. Seu conceito expressa flexibilidade e maleabilidade suficientes para "caracterizar os processos de sentidos subjetivos e significados gerados nas diversas áreas da vida social e de integrar as formas históricas e atuais de subjetivação produzidas nestes espaços" (GONZÁLEZ REY, 2005, pp. 207-208).

O conceito de subjetividade social abre um novo caminho para a investigação psicológica da dimensão subjetiva caracterizadora dos espaços sociais, possibilitando uma representação viva e dinâmica da rede de produções subjetivas integradoras das configurações subjetivas daqueles espaços. Nesse entendimento, González Rey assinala que a categoria de subjetividade social:

\begin{abstract}
Allows the explanation of how society, in its diverse levels, institutions, and processes, is configured recursively in all those diverse instances, making them living, contradictory, and heterogeneous social spaces, while also being configured in individuals whose active positions and behaviors are constituent of the different paths taken those social instances in their development (GONZÁLEZ REY, 2019, p.29).
\end{abstract}

\title{
Considerações Finais
}

O conjunto conceitual da Teoria da Subjetividade destaca o caráter aberto e processual de uma teoria orientada à compreensão e elaboração de modelos teóricos os quais consigam acompanhar a complexidade da subjetividade humana. Tais modelos não são a apreensão direta, total, conclusa do fenômeno 
investigado. Eles representam "ideias e construções em processo que não se reduzem ao momento em que formalmente estamos vivendo o 'espaço de pesquisa' com os participantes" (GONZÁLEZ REY, 2014, p.17).

A trama organizadora dos conceitos está mutuamente constituída. Isto implica em que alterações significativas relacionadas a determinado conceito tenham reverberações nos demais conceitos da teoria e, dessa forma, no sistema teórico geral por eles constituído. Essa dinâmica conceitual configura a Teoria da Subjetividade como um sistema que não descreve e qualifica, a priori, as produções subjetivas das experiências humanas. As categorias da teoria em questão ganham vida no curso da investigação, cuja congruência entre as múltiplas informações, as hipóteses e articulações teóricas do pesquisador, terá como expressão teórica do investigado, o modelo teórico emergente.

A teoria da Subjetividade avança em relação aos pressupostos teóricos consagrados em diferentes abordagens na psicologia, os quais tomam suas categorias como traduções a priori daquilo que é pesquisado. O pesquisador não encontrará nela fórmulas enquadradoras das múltiplas expressões da subjetividade humana. Assim, os desafios epistemológicos que o uso das categorias em discussão acarretam, apontam para processos de pensamentos não lineares, caracterizados pela reflexão, questionamento, curiosidade, confrontação teórica-metodológica frente ao pesquisado.

O valor heurístico de seus conceitos reside, precisamente, na geração de visibilidades aos aspectos subjetivos das experiências humanas, abrindo novas zonas de inteligibilidade teórica sobre questões que outras teorias não permitem. Nessa direção, os conceitos deixam de guiar a investigação desde suas definições para, então, serem um recurso à produção de novos saberes para o qual "a própria categoria é a base de novos significados que a enriquecem e estendem o seu campo de inteligibilidade" (GONZÁLEZ REY, 2014, p.16).

\section{Referências}

BATTISTI, C.A (org.). As voltas com as questões do sujeito: posições e perspectivas. Ijuí: Ed. Unijuí; Cascavel: Edunioeste, 2010.

CAIRES, E. Subjetividade e desenvolvimento na aprendizagem da música. In: 
CAMPOLINA, L.D.O; MORI, V.D. (orgs.) Diálogos com a teoria da subjetividade: reflexões e pesquisa. Curitiba: CRV, 2017.

GONZÁLEZ REY, F. Comunicación, personalidad y desarrollo. Habana: Editorial Pueblo y Comunicación, 1995.

Editorial Academia, 1996.

F. Problemas epistemológicos de la psicología. Habana: , F. Epistemología cualitativa y subjetividad. São Paulo:

EDUC. 1997.

F. La subjetividad: su significación para la ciencia psicológica. In: Odair FURTADO, Odair; GONZÁLEZ REY, Fernando (Orgs.). Por uma epistemologia da subjetividade: um debate entre a teoria sócio histórica e a teoria das representações sociais. São Paulo: Casa do Psicólogo, 2002.

, F. O social na psicologia e a psicologia social: a emergência do sujeito. Tradução de Vera Lúcia Mello Joscelyne. Petrópolis, RJ: Vozes, 2004.

F. Sujeito e subjetividade: uma aproximação históricocultural. Tradução: Raquel Souza Lobo Guzzo. São Paulo: Pioneira Thomson Learning, 2005.

, F. Psicoterapia, subjetividade e pós-modernidade: uma aproximação histórico-cultural. São Paulo: Thomson Learning, 2007a.

F. As categorias de sentido, sentido pessoal e sentido subjetivo: sua evolução e diferenciação na teoria histórico-cultural. Psicologia da Educação. São Paulo, 24, 1 sem. 2007b.

, F. Posmodernidad y subjetividad: distorciones y mitos. Revista de Ciências Humanas. UTP, $\mathrm{n}^{\circ} 37$. Diciembre, 2007c.

F. Subjetividad social, sujeto y representaciones sociales. Revista Diversitas-Perspectivas en Psicologia, vol.4, No 2, pp.225-243, 2008.

F. A questão das técnicas e os métodos na psicologia: da mediação à construção do conhecimento psicológico. In: BAHIA BOCK, Ana M. (org). Psicologia Compromisso Social. 2ed. rev. São Paulo: Cortez, 2009a.

F. Historical relevance of Vygotsky's work: its significance for a new approach to the problem of subjectivity in psychology. Outlines: Critical Practical Studies, 11, 59-73, 2009b.

, F. Epistemologia y ontología: un debate necesario para la psicología hoy. Revista Diversitas-Perspectivas en Psicología, V. 5, N 2, 2009c.

F. Las categorías de sentido, sentido personal, y sentido subjetivo en una perspectiva histórico-cultural: un camino hacia una nueva definición de subjetividad. Universitas Psychologica, Bogotá, Colombia, V.9, No.1, 
p. 241-253, ene-abr. 2010.

São Paulo: Cortez, 2011a.

F. Subjetividade e saúde: superando a clínica da patologia.

, F. El sujeto y la subjetividad en la psicología social. Un enfoque histórico-cultural. Buenos Aires: Noveduc, $2011 \mathrm{~b}$.

F. A configuração subjetiva dos processos psíquicos: avançando na compreensão da aprendizagem como produção subjetiva. In: Albertina Mitjáns Martinez, Beatriz Judith Lima Scoz, Marisa Irene Siqueira de Carvalho (orgs). Ensino e aprendizagem: a subjetividade em foco. Brasília: Liber Livros, 2012a.

F. Advancing on the concept of sense: subjective sense and subjective configurations in human development. In: M. Heideggard, A. Edwards, M. Fleer (orgs). Motives in children's development: cultural-historical approaches. 1ed. Cambridge: Cambridge University Press, v.1, pp 45-62, 2012b.

F. Ideias e modelos teóricos na pesquisa construtivointerpretativa. In: Albertina Mitjáns Martínez, Maurício Neubern, Valéria Mori (orgs.). Subjetividade contemporânea: discussões epistemológicas e metodológicas. Campinas, SP: Editora Alínea, 2014.

F. Advancing the topics of social reality, culture and subjectivity from a cultural-historical standpoint: moments, paths and contradictions. Journal of Theoretical and Philosophical Psychological, vol.36, No. 3, 175-189, 2016.

F. Entrevista com Fernando González Rey. In: Mori, V.D. Campolina, L.D.O (orgs). Diálogos com a teoria da subjetividade: reflexões e pesquisas. Curitiba: CRV, 2017a.

F. Advancing in subjectivity from a cultural-historical perspective: unfoldings and consequences for cultural studies today. In: M. Fleer, F. González Rey; N. Veresov (Eds.). Perezhivanie, emotions and subjectivity: Advancing Vygotsky's legacy. Singapore: Springer, 2017b, p. 173-194.

F. Subjectivity as a new theoretical, epistemological, and methodological pathway within cultural-historical psychology. In: GONZÁLEZ REY, F.; MITJÁNS MARTINEZ, A.; MAGALHÃES GOULART, D. (Orgs).

Subjectivity within cultural-historical approach. Perspectives in cultural-historical research 5. Singapore: Springer, 2019.

GONZÁLEZ REY, F; MITJÁNS MARTINEZ, A. Una epistemología para el estudio de la subjetividad: sus implicaciones metodológicas. Chile: Psicoperspectivas, 15 (1), 5-16, 2016. 
._. Subjetividade. Teoria, epistemologia e método. Campinas, Alínea, 2017.

GONZÁLEZ REY, F; PATIÑO, J.F. La epistemología cualitativa y el estudio de la subjetividad em una perspectiva cultural-histórica. Conversación com Fernando González Rey. Revista de Estudos Sociales, 60, 120- $128 . \quad$ DOI: https://doi.org/10.7440/res60.2017.10, 2017.

DE LIBERA, A. Arqueologia do sujeito: nascimento do sujeito. Tradução: Fátima Conceição Murad. São Paulo: Editora Fap-Unesp, 2013.

ROSSATO, M, \& MITJÁNS MARTÍNEZ, A. Desenvolvimento da subjetividade: análise de histórias de superação das dificuldades de aprendizagem. Psicologia Escolar e Educacional, 17 (2), 289-298, 2013.

VYGOTSKY, L. A construção do pensamento e da linguagem. Tradução: Paulo Bezerra. São Paulo: Martins Fontes, 2000.

Pensamento e Linguagem. Tradução: Miguel Serras Pereira. Relógio D’Água Editores, Dezembro, 2007. 